\title{
Behavioural and psychological responses of lower educated smokers to the smoke-free legislation in Dutch hospitality venues: A qualitative study
}

Citation for published version (APA):

van der Heiden, S., Gebhardt, W. A., Willemsen, M. C., Nagelhout, G. E., \& Dijkstra, A. (2013).

Behavioural and psychological responses of lower educated smokers to the smoke-free legislation in Dutch hospitality venues: A qualitative study. Psychology \& Health, 28(1), 49-66.

https://doi.org/10.1080/08870446.2012.712695

Document status and date:

Published: 01/01/2013

DOI:

10.1080/08870446.2012.712695

Document Version:

Publisher's PDF, also known as Version of record

Document license:

Taverne

Please check the document version of this publication:

- A submitted manuscript is the version of the article upon submission and before peer-review. There can be important differences between the submitted version and the official published version of record.

People interested in the research are advised to contact the author for the final version of the publication, or visit the DOI to the publisher's website.

- The final author version and the galley proof are versions of the publication after peer review.

- The final published version features the final layout of the paper including the volume, issue and page numbers.

Link to publication

\footnotetext{
General rights rights.

- You may freely distribute the URL identifying the publication in the public portal. please follow below link for the End User Agreement:

www.umlib.nl/taverne-license

Take down policy

If you believe that this document breaches copyright please contact us at:

repository@maastrichtuniversity.nl

providing details and we will investigate your claim.
}

Copyright and moral rights for the publications made accessible in the public portal are retained by the authors and/or other copyright owners and it is a condition of accessing publications that users recognise and abide by the legal requirements associated with these

- Users may download and print one copy of any publication from the public portal for the purpose of private study or research.

- You may not further distribute the material or use it for any profit-making activity or commercial gain

If the publication is distributed under the terms of Article $25 \mathrm{fa}$ of the Dutch Copyright Act, indicated by the "Taverne" license above, 


\section{Behavioural and psychological responses of lower educated smokers to the smoke-free legislation in Dutch hospitality venues: A qualitative study}

Sander Van der Heiden, Winifred A. Gebhardt, Marc C. Willemsen, Gera E. Nagelhout \& Arie Dijkstra

To cite this article: Sander Van der Heiden, Winifred A. Gebhardt, Marc C. Willemsen, Gera E. Nagelhout \& Arie Dijkstra (2013) Behavioural and psychological responses of lower educated smokers to the smoke-free legislation in Dutch hospitality venues: A qualitative study, Psychology \& Health, 28:1, 49-66, DOI: 10.1080/08870446.2012.712695

To link to this article: https://doi.org/10.1080/08870446.2012.712695

曲 Published online: 09 Aug 2012.

Submit your article to this journal

山 Article views: 355

View related articles $₫$

Citing articles: 1 View citing articles $ک$ 


\title{
Behavioural and psychological responses of lower educated smokers to the smoke-free legislation in Dutch hospitality venues: A qualitative study
}

\author{
Sander Van der Heiden ${ }^{\mathrm{a}}$, Winifred A. Gebhardt ${ }^{\mathrm{a} *}$, Marc C. Willemsen ${ }^{\mathrm{bc}}$, Gera \\ E. Nagelhout ${ }^{\text {bc }}$ and Arie Dijkstra ${ }^{\mathrm{d}}$ \\ ${ }^{a}$ Department of Clinical, Health and Neuropsychology, Leiden University, Leiden, \\ The Netherlands; ${ }^{b}$ Department of Health Promotion, CAPHRI, Maastricht University, \\ Maastricht, The Netherlands; ' $S T I V O R O$ for a Smoke Free Future, The Hague, \\ The Netherlands; ${ }^{d}$ Department of Social Psychology, University of Groningen, \\ Groningen, The Netherlands
}

(Received 11 February 2012; final version received 11 July 2012)

\begin{abstract}
Objective: In 2008, smoke-free legislation was implemented in hospitality venues (HV) in the Netherlands. We investigated how continuing smokers with a lower educational background respond behaviourally and psychologically to the legislation and the norm it communicates.

Design: In 2010, 18 lower-educated daily smokers were interviewed. Transcripts were analysed with MAXQDA software. Theories of selfawareness and social in- and exclusion were applied to interpret findings. Results: Smokers had become more self-aware and the experience of a more negative norm surrounding smoking had made them reevaluate their smoking. Smokers had also become more self-aware of their own smoking, both in HV and in general. Feelings of increased social exclusion were reported. Participants dealt with the increased awareness and feelings of social exclusion in different ways depending on their evaluation of the smoking ban, changes in attitude towards own smoking, changes in HV patronage and changes in smoking behaviour.

Conclusion: Theories of self-awareness and social in- and exclusion were useful in understanding consequences of a HV smoking ban on continuing smokers. Four different types of responses were identified, i.e. (1) actively trying to quit, (2) socially conscious smoking, (3) feeling victimised and (4) rejecting the norm. Implications for future smoke-free legislation are discussed.
\end{abstract}

Keywords: smokers; policy impact; smoking ban; interviews; lower socioeconomic status; self-awareness; social exclusion

\section{Introduction}

In the Netherlands, with a population of 16.5 million, smoke-free legislation in hospitality venues (HV) was introduced on 1 July 2008 to protect employees from the harmful effects of second hand smoke. In Dutch HV, smokers are allowed to smoke

*Corresponding author. Email: gebhardt@fsw.leidenuniv.nl 
in designated smoking rooms (if available) or outside. The new regulation reduced smoking in bars from $88 \%$ to $34 \%$ (Nagelhout, Mons, et al., 2011) and increased quit attempts, especially among frequent bar visitors (Nagelhout, Willemsen, \& de Vries, 2011). However, its effectiveness has been much lower than in Ireland and France, for example, where smoking in bars was reduced to 3\% (Nagelhout, Mons, et al., 2011). Furthermore, there was less support for the ban six months after its instatement compared to Ireland and France $(44 \%$ vs. $80 \%$ and $67 \%$, respectively; European Commission, 2009).

Smoke-free legislation may communicate to smokers that it disapproves of the act of smoking and - to some extent - of smokers, which in turn may negatively affect their social status (Bayer \& Stuber, 2006; Bell, McCullough, Salmon, \& Bell, 2010; Ritchie, Amos, \& Martin, 2010a). As a result of perceptions of reduced acceptability of smoking, some smokers may reduce their smoking and strengthen their intention to quit smoking (Alamar \& Glantz, 2006; Brown, Moodie, \& Hastings, 2009; Hargreaves et al., 2010). However, it may also invoke feelings of being rejected, and of being stigmatised, as it is perceived that others become more negative of them as a smoker due to the stronger non-smoking norm that accompanies the enforcement of the measure (Chapman \& Freeman, 2008; Louka, Maguire, Evans, \& Worrell, 2006, Ritchie et al., 2010a). This may make some smokers feel less willing and/or able to quit smoking, which in turn may cause their smoking behaviour to become more robust (Warner \& Burns, 2003). Although aimed at protecting employees by eliminating smoking in $\mathrm{HV}$, the ban is thus also likely to affect those who continue to smoke.

There have been a few, mostly qualitative, studies on the effects of tobacco denormalisation through smoke-free legislation on continuing smokers. For instance, Ritchie et al. (2010a) and Ritchie, Amos, and Martin (2010b) focused on the social context of smoking and on stigmatisation processes in Scotland, and found that smokers felt more stigmatised than before the smoke-free policy, even when they were not smoking. Hargreaves et al. (2010) found that the social context was mainly responsible for a change in smoking behaviour and that whether smokers cut down on their smoking was primarily due to constraints that were imposed by the smokefree legislation. Bell et al. (2010) used a more explorative approach looking at how smokers experienced and responded to the denormalisation of tobacco use in Canada. Their main results indicate that smokers perceive that smoking policies are overly restrictive and that non-smokers have more and more 'claimed' public space.

These studies generally did not consider the situation before the smoke-free legislation came into effect, making it difficult to draw conclusions on whether a change had occurred. To account for this, temporal comparisons were used in this study. A temporal comparison is made when one compares one's present state with that at an earlier point in time (Dijkstra, Borland, \& Buunk, 2007; Menninga, Dijkstra, Gebhardt, \& Siero, 2011). As such, temporal comparisons are people's construction of changes over time and reflect a general human psychological tendency to make sense of the world and to understand one's experiences. This technique was chosen, because the psychological state that reflects an evaluation of the perceived changes in circumstances of the smoker is far more likely to influence smokers than the factual, actual changes. Findings of previous research indeed indicate that such temporal comparisons are predictive of smoking relapse behaviour (Menninga et al., 2011). Consequently, to assess changes perceived by smokers since the smoke-fee legislation was introduced, we asked respondents to think back to the 
time when the HV smoking ban was installed, and to compare their present situation to that situation in the past (see 'Methods' section for a further explanation).

The present study used an explorative approach aiming to gain more insight into how Dutch smokers responded to the smoke-free legislation, both psychologically as from a behavioural perspective. Moreover, the focus of the present study is specifically on smokers with a lower educational background, as a highly relevant indicator of (lower) SES (Schaap \& Kunst, 2009). The level of education is strongly associated with smoking, even after adjusting for income (Huisman et al., 2012). Smokers from a lower SES background have been found to be more nicotine dependent, have lower quitting self-efficacy and are more likely to have no intention to quit than higher SES smokers (Siahpush, McNeill, Borland, \& Fong, 2006). In addition, they show less concern about the harms of smoking (Sorensen, Emmons, Stoddard, Linnan, \& Avrunin, 2002), experience more stress and depend more on smoking to cope with it (Siahpush et al., 2006), and report less social support when actually wanting to quit smoking (Sorensen et al., 2002).

Correspondingly, the prevalence of smoking in lower SES groups is higher than in higher SES groups, and quit attempts among lower SES smokers are less likely to be successful (Reid, Hammond, Boudreau, Fong, \& Siahpush, 2010). In the Netherlands, as in other developed countries, large differences exist in smoking between men and women of a lower SES versus higher SES. For example, in 2010, $34 \%$ of men with a lower SES smoked whereas $22 \%$ of men with a higher SES smoked. Among women, in 2010, 33\% with a lower SES smoked versus $18 \%$ of women with a higher SES (Nagelhout, De Korte, et al., 2011; Nagelhout et al., 2012).

Indeed, most elements that are part of one's lifestyle, including smoking behaviour, are assumed to be strongly socially embedded. They are practices that are developed within groups, taking into account the reality of circumstances that correspond to being part of that group (Poland et al., 2006). That is, the freedom to determine one's own lifestyle is limited to the social constraints that apply to a specific group, such as lower SES. Thus, the life choices are to a large extent dependent on the life chances, even in times when social structures are undergoing major transitions (Cockerham, Rutten, \& Abel, 1997).

In short, the present qualitative study was conducted to gain insight in the effects of smoking restriction policy in the Dutch hospitality industry on continuing lower SES smokers. Structured in-depth interviews with 18 continuing low SES smokers were conducted and interpreted. The findings may help to improve the design and implementation of future smoking restrictions with regard to minimising unwanted side-effects, such as more robust smoking behaviour and reduced receptivity to future smoking restrictions, as well as maximising possible side-effects, specifically reduced cigarette consumption among lower SES smokers.

\section{Methods}

\section{Participants}

In the Netherlands relatively many smokers do not accept the smoking ban compared to other countries (European Commission, 2009; Mons et al., 2012), and to represent this group we also recruited through a 'Smokers' Rights Group' $(n=2)$. Smokers were also recruited through STIVORO, the Dutch expert centre on tobacco control, representing a large percentage of smokers who have the intention to quit smoking $(n=8)$. Participants were also recruited through posters in a middle-sized city 
Table 1. Information of the participants.

\begin{tabular}{|c|c|c|c|c|c|c|c|c|c|}
\hline \multirow[b]{2}{*}{ Part. (\#) } & \multirow[b]{2}{*}{ Sex } & \multirow[b]{2}{*}{ Age } & \multirow{2}{*}{$\begin{array}{l}\text { Educ. } \\
\text { level }^{\mathrm{a}}\end{array}$} & \multirow{2}{*}{$\begin{array}{l}\text { Daily } \\
\text { cig. (\#) }\end{array}$} & \multirow{2}{*}{$\begin{array}{l}\text { Recruitm. } \\
\text { source }^{\mathrm{b}}\end{array}$} & \multicolumn{3}{|c|}{ HV patronage frequency ${ }^{c}$} & \multirow{2}{*}{$\begin{array}{c}\Delta \mathrm{HV} \\
\text { patronage } \\
\text { frequency } \\
\text { since ban }\end{array}$} \\
\hline & & & & & & Bar & Night club & Restaurant & \\
\hline 1 & M & 45 & VMBO & 25 & News paper & M & M & W & $\downarrow$ \\
\hline 2 & M & 20 & MBO & 10 & Poster & W & M & M & $\downarrow$ \\
\hline 3 & M & 48 & LBO & 25 & SRG & $<\mathrm{M}$ & $<\mathrm{M}$ & $<\mathrm{M}$ & $\downarrow$ \\
\hline 4 & $\mathrm{~F}$ & 45 & $\mathrm{MBO}$ & 40 & STIVORO & $\mathrm{M}$ & $<\mathrm{M}$ & M & $\downarrow$ \\
\hline 5 & $\mathrm{~F}$ & 37 & MBO & 15 & STIVORO & M & $<\mathrm{M}$ & $<\mathrm{M}$ & $\uparrow$ \\
\hline 6 & M & 20 & VMBO & 20 & STIVORO & M & $<\mathrm{M}$ & $<\mathrm{M}$ & $\uparrow$ \\
\hline 7 & M & 29 & MBO & 30 & Poster & M & $<\mathrm{M}$ & $\mathrm{D}$ & $\downarrow$ \\
\hline 8 & $\mathrm{~F}$ & 32 & VMBO & 20 & STIVORO & M & $<\mathrm{M}$ & M & $\downarrow$ \\
\hline 9 & $\mathrm{~F}$ & 24 & VMBO & 25 & GP & W & $<\mathrm{M}$ & $<\mathrm{M}$ & $\downarrow$ \\
\hline 10 & $\mathrm{~F}$ & 41 & MBO & 15 & SRG & $<\mathrm{M}$ & $<\mathrm{M}$ & W & $\downarrow$ \\
\hline 11 & $\mathrm{~F}$ & 20 & MBO & 26 & STIVORO & W & $<\mathrm{M}$ & $<\mathrm{M}$ & 0 \\
\hline 12 & M & 24 & VMBO & 15 & STIVORO & M & $<\mathrm{M}$ & $<\mathrm{M}$ & 0 \\
\hline 13 & M & 24 & MBO & 10 & STIVORO & W & $\mathrm{M}$ & M & 0 \\
\hline 14 & M & 18 & VMBO & 8 & Friend & M & W & M & 0 \\
\hline 15 & $\mathrm{~F}$ & 44 & MBO & 19 & STIVORO & $<\mathrm{M}$ & $<\mathrm{M}$ & $<\mathrm{M}$ & $\downarrow$ \\
\hline 16 & M & 32 & MBO & 25 & Friend & M & $<\mathrm{M}$ & M & $\downarrow$ \\
\hline 17 & $\mathrm{~F}$ & 23 & MBO & 8 & Friend & $<\mathrm{M}$ & $<\mathrm{M}$ & M & 0 \\
\hline 18 & $\mathrm{~F}$ & 24 & MBO & 19 & GP & M & W & $<\mathrm{M}$ & 0 \\
\hline
\end{tabular}

Notes: ${ }^{\mathrm{a}} \mathrm{VMBO}=\mathrm{UK}$ GCSE's At $\mathrm{C}$ level/US 10th Grade, $\mathrm{MBO}=$ Vocational Education, $\mathrm{LBO}=$ Lower Vocational Education.

${ }^{\mathrm{b}} \mathrm{SRG}=$ Smokers Right Group, GP $=$ General Practitioner.

${ }^{\mathrm{c}} \mathrm{D}=$ daily, $\mathrm{W}=$ weekly, $\mathrm{M}=$ monthly, $<\mathrm{M}=$ less than monthly.

in the Netherlands, an advertisement in a local news paper $(n=3)$. Five participants indicated that their GP or their friends told them of the study. Potential participants filled in a short online survey which assessed inclusion criteria, i.e. current daily smoking, daily smoking before 1 July 2008, and an educational level that did not exceed vocational education. To ensure that respondents were exposed to the smokefree legislation (Borland \& Owen, 1995), we only included smokers who indicated they visited bars, restaurants or night clubs monthly or, if less than monthly, if they visit HV 'less frequently' or 'much less frequently' since the smoking ban was instated.

Participants who met the inclusion criteria $(n=18)$ were contacted by telephone or e-mail and informed that this study aimed to learn more about their perceived changes in their thinking about smoking, in smoking behaviours, in patronage of bars and in their social environment in response to the public smoking ban, after which they were asked to participate. Nine females and nine males with an average age of 30 (SD =10, range: 18-48) participated. Birth countries were the Netherlands $(n=17)$ and Spain $(n=1$; this interview was conducted in English). Participants were from different regions within the Netherlands. Additional information on participants is provided in Table 1.

\section{Interviews}

Interviews were conducted in person at the home of participants $(N=17)$ and at the Faculty of Social Sciences in Leiden $(N=1)$ two to two-and-a-half years after 
Table 2. Topics assessed during the interviews.

Topics

Expectations of the smoking ban

Appreciation of the ban

Implementation/Communication

Differences between bars, night clubs, restaurants

Appreciation of (significant) others

Change in appreciation since its instatement

Compliance of self, others in HV

HV patronage changes

Frequency, visiting of particular venues

Smoking behaviour in HV (and of others in HV)

Feelings while standing outside/in smoking room*

\author{
General changes \\ Smoking behaviour/thoughts of \\ quitting/quit attempts \\ Thinking about health risks \\ for others \\ Norm changes \\ Approval/number of smokers in \\ social environment \\ Perceived approval of society \\ Smoker identity changes
}

Note: *Added after discussion of the first two interviews.

instatement of the HV smoking ban. One male researcher ( $\mathrm{SH}$ ) conducted the interviews. Each participant was reimbursed with a gift coupon of 10 euros (13 US dollars). A semi-structured interview schedule was used to guide participants through the interview that consisted of the topics presented in Table 2. Interviews were planned to last for 45-60 minutes. The average length of the interviews was 53 minutes (range: $30-1: 20$ min.).

Before the start of the interview, the purpose and content was briefly explained, after which oral informed consents were obtained. Participants were informed that they could withdraw from the study at any stage without having to give any reason for this. In the introduction the privacy and uniqueness of the interview was underscored, as well as the importance of establishing an honest and realistic view of their every-day experiences as a smoker.

Then, the actual interview started. Questions were open ended and answers were further explored by the interviewer. First, participants were asked to try to remember where they were and what they did when the ban was implemented, by having them go back in time by referring to a soccer game between the Netherlands and Russia at the European Championship that was played 10 days before implementation of the ban. Then, their expectations of the ban beforehand were explored and how the ban affected them in general and with regard to specific domains (Table 2) using temporal comparisons (Albert, 1977; Dijkstra et al., 2007). The reference point in this case was the smoking ban in HV. An example of a question formulated as a temporal comparison that was used during the interviews was: 'In comparison to before the ban, how did [your patronage of bars] change - if at all?'. The atmosphere of all interviews was experienced by the interviewer as open and 'at-ease'.

Interviews were recorded and transcribed. In an iterative process, after transcription of the first two interviews, two researchers (first and second author) decided to add one topic, namely 'feelings while standing outside/in a smoking room'.

\section{Ethics}

The study complied with and was approved off by the board of ethics of the Faculty of Social Sciences at the University of Leiden. Participants were informed that they 
could withdraw from the study at any stage. To guarantee confidentiality and anonymity, names of people, organisations and geographical locations were deleted from the transcripts.

\section{Data analysis}

Interviews were transcribed and resulting transcripts were analysed using MAXQDA (Kuckartz, 2007) qualitative data analysis software. A thematic analysis was applied (Braun \& Clarke, 2006), which means that we identified patterned responses or meaning within the dataset. In the first stage of data analyses, data were coded without a specific theoretical framework in mind. For five of the transcripts this was done by the first two authors ( $\mathrm{SH} \& \mathrm{WG}$ ), who discussed and agreed upon the main themes. The themes that were identified were used to code all other interviews by the first author $(\mathrm{SH})$. Then, in a second step, an inductive or bottom-up analysis was used, which means that the themes that were identified from the transcripts were incorporated into larger themes. Based on the content of the categorisations, we (SH $\&$ WG) identified self-awareness theory and social exclusion as suitable frameworks for interpreting the data. These two frameworks were chosen because a majority of participants felt that as a result of the HV smoking ban, their smoking status excluded them from public venues, and thus, in a sense, from society as a whole. Furthermore, some answers of participants reflected the process of stigmatisation. For example, some participants felt that their smoking status over time was being increasingly negatively evaluated by others, and had therefore more negative consequences to them (for a further explanation of the theoretical frameworks, see next section). During a final step of coding, these frameworks were used to categorise the data. This was done by the first author $(\mathrm{SH})$, but all decisions in this respect were discussed extensively with the second author (WG). Quotes that were thought to be most representative and illustrative of their respective categories were chosen to be used in the results section in consultation with all co-authors.

\section{Theoretical framework}

Results have been interpreted using insights from self-awareness theory (Duval \& Wicklund, 1972; Silvia \& Duval, 2001) and social exclusion theory (Abrams, Hogg, $\&$ Marques, 2005). Self-awareness (SA) theory states that individuals compare themselves to a standard, but only when they are highly focused on the self. Smoking in $\mathrm{HV}$ is less of an automatic, unconscious behaviour than it was before the smoking ban came into effect, because smokers have to decide to go to a smoking room or outside to smoke (Ritchie, Amos, \& Martin, 2010b). Additionally, self-awareness is raised, because they feel observed by others while smoking (Carver \& Scheier, 1978). This increased self-awareness leads them to self-evaluate and perceive a discrepancy between their behaviour (i.e. smoking) and the standard that the smoking ban communicates (i.e. non-smoking) (Duval \& Wicklund, 1972). This behaviourstandard incongruence leads smokers to experience an aversive emotional state which motivates individuals to restore consistency (Duval \& Wicklund, 1972). Furthermore, since the smoke-free legislation is likely to result in the physical segregation of smokers and non-smokers, i.e. by excluding smoking inside HV, continuing smokers are likely to feel (more) socially excluded, especially those to 
whom HV serve an important social function (McLaughlin-Volpe, Aron, Wright, \& Lewandowski, 2005). Therefore, smokers are likely to react to this norm, both psychologically and behaviourally.

After careful consideration of both theories of self-awareness and social exclusion, we identified (a combination of) the following strategies smokers could use to restore consistency between norms and behaviour and deal with feelings of social exclusion: (1) they can bring their smoking behaviour and attitudes towards (own) smoking more in line with the proposed standard and attempt to regain inclusion (i.e. become more negative about their smoking and/or smoke less/quit smoking); (2) they can avoid situations (i.e. HV) in which they are confronted with this incompatible standard and/or (3) they may question the legitimacy of the standard itself and oppose to it.

\section{Results}

From the interviews and using the aforementioned frameworks, we identified two overarching themes and seven topics (Table 3), which are described in more detail below.

\section{Experience of $\mathrm{HV}$ ban}

With regard to how participants experienced the smoking ban and the norm it communicates, three themes could be identified: (a) changes in the norm with regard to smoking/being a smoker, (b) an increase in awareness of smoking/being a smoker and (c) feelings of social exclusion as a result of the HV smoking ban.

\section{Norm changes}

From the interviews, we found that the majority of participants clearly experienced a change in norms concerning smoking that was not necessarily attributable to the smoke-free legislation in HV. Not only did they report that disapproval of their smoking increased over time, they also reported to witness increasingly less smoking and smokers in their surroundings.

Fifteen years ago, it was not like, 'are you a smoker or a non-smoker'? You either smoked, or you didn't, it didn't matter. But now, non-smoker is no longer even a category, you know. I mean, nowadays, I get the feeling it is more like, 'are you normal, or are you a smoker'? (\#9, 24F, $25 \mathrm{cig} /$ day $)$

Table 3. Resulting topics.

\begin{tabular}{|c|c|}
\hline Topics & \\
\hline $\begin{array}{l}\text { I. Experience of } \mathbf{H V} \text { ban } \\
\text { a. Norm changes } \\
\text { b. Increased self-awareness } \\
\text { c. Social exclusion }\end{array}$ & $\begin{array}{l}\text { II. Effects of HV ban } \\
\text { a. Evaluation of the smoking ban } \\
\text { b. Change in attitude towards (own) smoking } \\
\text { and smoking status } \\
\text { c. Change in patronage } \\
\text { d. Change in smoking behaviour }\end{array}$ \\
\hline
\end{tabular}


Both the social norm and descriptive norm have thus changed over time according to most participants. In addition, some participants expressed the feeling that the society disapproved of (their) smoking more nowadays (i.e. injunctive norm).

All these programs about quitting smoking and all the publicity, the media, the government, everybody is against smoking (\#4,45M, $40 \mathrm{cig} /$ day)

Some participants reported perceiving especially ex-smokers (as compared to never-smokers) to be more critical of (their) smoking.

I think non-smokers consist of two categories. Non-smokers who never smoked, they take it all for granted. And you have non-smokers who have once smoked and have quit. They have become severely anti-smoking. (\#8, 32F, $20 \mathrm{cig} / \mathrm{day})$

In other words, the social norm was perceived by most respondents to have changed quite substantially during the past few years in the direction of more disapproval of smoking. The perception was based on several external signals, such as negative responses from non-smokers. The HV smoking ban was perceived as part of this broader, general societal development.

\section{Increased self-awareness}

The majority of smokers reported that the smoking ban had increased their selfawareness (SA). We identified two ways in which their SA was increased. First, participants reported that smoking in HV had become a more conscious act.

Because if you just sit there and you are allowed to smoke everywhere, you just continue smoking and now you have to think about it. (\#2, 20M, $10 \mathrm{cig} /$ day)

Second, the ban itself served as a reminder of negative aspects of (their) smoking. Some participants reported that it reminded them of the detrimental effects on (their) health.

It is like everybody is increasingly aware of how unhealthy smoking is (\#9, 24F, 25 cig/day)

Places where you can grab a smoke when you want to are on the decline. So then you already are like, 'okay, it is thus actually not at all normal, it is really unhealthy'. That awareness increases. (\#16, 32M, $25 \mathrm{cig} /$ day)

Some participants mentioned several other negative features of smoking, such as becoming more aware of that with smoking and buying cigarettes they were just sponsoring the tobacco industry, increased awareness of the unnaturalness of the act of smoking, and it raised awareness of their addiction to smoking cigarettes. Thus, the HV smoking ban has made most respondents more aware of smoking and the negative aspects connected to it.

\section{Social exclusion}

When asked how standing and smoking in a designated smoking area (in a smoking room or outside) made them feel, some participants reported that they felt socially excluded; smokers reported feeling 'criminal', 'different' and 'outcast'. 
You get excluded everywhere; you always have to smoke outside, you can't smoke in the office, no longer in a restaurant. So you do feel like a criminal in the winter near a 'rookpaal' [i.e. ashtrays provided in designated smoking areas], shivering in the rain. (\#8, 32F, $20 \mathrm{cig} /$ day)

Yes, you feel so different or just pushed away. I don’t know, just different. (\#17, 23, $8 \mathrm{cig} /$ day)

Furthermore, some participants felt that it was not just the smoking ban that made them feel excluded, but that this process had been going on for a longer time period.

You actually become a pariah. You aren't exposed to it [i.e. smoking] as much anymore.

(\#1, 45M, $25 \mathrm{cig} /$ day)

Some smokers reported that the smoke-free legislation led them to feel worse about their smoking behaviour and being a smoker. Smoking inside a smoking room or outside and seeing others smoke outside public venues that are smoke-free led some participants to label their smoking in a (more) negative manner.

That is because you are being confronted with your own weaknesses of course. [...] I don't like to feel dumb and weak but that is what is being created there $(\# 4,45 \mathrm{~F}$, $40 \mathrm{cig} /$ day)

And then you see people smoking in front of the building and then you think 'hey, look at them standing there', but yeah, that is also what I do. And it is pathetic actually, to stand there in front of a building, smoking. (\#1, 45 M, $25 \mathrm{cig} /$ day)

In addition, the smoking ban was seen by some participants to have more general and far-reaching consequences; they feel they are being deprived of what they perceive to be basic rights (e.g. going out) they have within the society.

But in public spaces I understand less, because there are people addicted and not addicted in the society and you have to... we have to live too, to be entertained and to go to places, to buy stuff in the supermarket. (\#5,37F, $15 \mathrm{cig} / \mathrm{day})$

Thus, the HV smoking ban and related events made some participants feel less tolerated by others in general. As a result, some of them became less accepting of their own smoking, while others quite clearly felt that smokers had become more and more victims of 'stigmatisation'. The latter group also felt that this tendency of others to blame them as a smoker was unjustified, as in a free society it should be their own decision whether they smoke or not.

\section{Effects of $\mathrm{HV}$ ban}

Overall, we identified four different themes among responses that continuing smokers reported on the effects of the HV smoking ban: (a) evaluation of the smoking ban, (b) changes in attitude towards (own) smoking and smoking status, (c) changes in patronage of $\mathrm{HV}$ after the ban was instated and (d) changes in smoking behaviour in $\mathrm{HV}$, in general.

\section{Evaluation of the smoking ban}

Participants reported both positive and negative characteristics of the ban. We identified three more general reasons why the ban was evaluated in a positive way. First, some continuing smokers considered it to be a positive thing for non-smokers. 
Previously, you were allowed to smoke everywhere actually. In public venues, yes wherever you were and I can imagine as a non-smoker that it bothers you. So I think it is a good thing that people are no longer smoking in public places or in restaurants. (\#1, $45 \mathrm{M}, 25 \mathrm{cig} /$ day)

Second, some mentioned the ban's likely beneficial effects on public health, through an increased awareness of the negative health effects of smoking and decrease in smoking overall (e.g. uptake among youth).

If you read now about the negative consequences of smoking and... yes, just by getting more knowledge about it you get a better understanding for it, for the ban. (\#13, 24M, $10 \mathrm{cig} /$ day)

Third, going out to restaurants was mentioned to have become more enjoyable (as opposed to bars) by most participants.

But it is just so much nicer. Because imagine that you just started eating, but the people next to you are already finished and would smoke. Then it is actually quite annoying, if I look back on it now. (\#17, 23F, 8 cig/day)

Also, several negative aspects of the ban were mentioned by some participants. One reason for a negative evaluation was participants' perception of unclear grounds and insufficient (constituent) support for the ban.

I think it is such nonsense, unbelievable, because yes, back then $80 \%$ of the Dutch people smoked. (\#7, 29M, $30 \mathrm{cig} / \mathrm{dag})$

Also because I think that many non-smokers are not really bothered by the smell of smoke in a cafe $(\# 10,41 \mathrm{~F}, 15 \mathrm{cig} /$ day $)$

A second reason for a negative evaluation was that, it was regarded by some as limiting their freedom as well as reducing their opportunities for socialising.

I find the patronizing of the government just bad. I don't approve of that. I think people should always be able to choose for themselves whether they want to smoke or not. How healthy or unhealthy it may be. They have to realize that they themselves were responsible for their addiction. You can tell how bad it is, but you shouldn't say things like 'you can do this' or 'you can't do that'. (\#16, 32M, $25 \mathrm{cig} / \mathrm{day})$

It was mentioned that going out, primarily to bars, had become less enjoyable. Smoking rooms, in particular, were mentioned to be uncomfortable, because of the lack of ventilation, stench of smoke and the perception of smoking in a smoking room being extra unhealthy.

I didn't like that at all, because everybody is standing there [i.e. in a smoking room] puffing and you nearly choke. You don't even have to smoke there. You will take in the nicotine automatically. Also, it is just not nice to smoke anymore [...] if you are in such a tiny place, while everybody is puffing. That alone causes you to have pain in your throat. (\#18, 24F, 19 cig/day)

Lastly, they also mentioned that smoking for them is connected to going out, especially to drinking in bars.

I thought it was very strange. Because in a place at night, where there are a lot of smokers, it is very strange to forbid it. ( $\# 5,37 \mathrm{~F}, 15 \mathrm{cig} / \mathrm{day})$

In short, both positive and negative aspects of the HV smoking ban were reported. Positive evaluations concerned the advantages for non-smokers and the 
clean air in restaurants, which was experienced to be advantageous for all, including non-smokers. On the other hand, most participants felt that the grounds for the HV smoking ban, particularly in bars, were unclear or unjustified. In addition, they reported that going-out had become less enjoyable: while smoking in the past (before the ban) had been an integral part of the experience, they now had go outside or to designated smokers' rooms to be able to smoke on a night's out.

\section{Attitude towards own smoking and smoking status}

Most participants reported to think and feel more negative about their smoking and smoking status. The reasons for this were that they no longer or to a lesser degree wanted to identify with their own smoking and their image of what constitutes a smoker. Participants became more negative about their smoking because they perceived that it had become more of an antisocial behaviour.

That you indeed can look at that group of people on the street who are standing there like that smoking and then I think like 'I don't want other people looking at me like that at all, I don't want anybody to have that image of me'. (\#9, 24F, $25 \mathrm{cig} / \mathrm{day}$ )

Another reason why some participants have become more negative about their smoking is because they recognised more the negative properties of their smoking, e.g. its addictive nature and negative consequences of smoking for their health.

Before, I was like 'whatever', you know, 'stop whining about it'. But I do notice for myself that I am increasingly uncomfortable with it. 'And can you identify, why that is?' Well, because I just know that it is unhealthy. (\#9, 24F, $25 \mathrm{cig} /$ day)

\section{Patronage}

Some participants reported that patronage of $\mathrm{HV}$ did not change, because other factors besides smoking, such as the atmosphere, were more important than the opportunity to smoke. As a result of the ban, some participants reported that they visited bars less often, avoided bars completely, or actively searched for and visited non-compliant bars. One reason for avoidance that was mentioned was that the atmosphere in bars was less enjoyable.

In some bars you were allowed to smoke inside and in others you weren't. So then I went to bars where it was allowed. And at a certain point, it wasn't allowed there anymore either. And then I stopped going. After that, I tried to go there twice, but I missed the pleasurable atmosphere and a tasty cigarette with a drink. (\#7, 29 M, $30 \mathrm{cig} /$ day)

And you can see a lot all of a sudden. That makes it much less enjoyable it seems, because the smoke seemed to make it a little smaller or something. (\#2, $20 \mathrm{M}, 10 \mathrm{cig} / \mathrm{day})$

Other reasons mentioned by some participants for reduced patronage or avoidance were the importance of smoking combined with a drink, weather conditions, i.e. having to stand outside to smoke in the winter, and being occupied constantly with going outside or not.

Because that cigarette is more important to me than a cup of coffee. That's why we don't go out to hospitality venues anymore. (\#4, 45 F, 40 cig/day)

You can only sit there like, gosh, am I going outside for a smoke or not. That kind of spoils the fun of the whole night entirely. (\#7, $29 \mathrm{M}, 30 \mathrm{cig} /$ day) 
Thus, some respondents indicated that they visit HV far less frequently after the ban, because smoking is no longer an automatic and easy element of going-out.

\section{Smoking behaviour in $\mathrm{HV}$}

While some participants reported that their smoking behaviour in $\mathrm{HV}$ and, in general, had not changed, the majority of participants reported to smoke less in HV after the ban. Participants reduced their smoking in HV for two main reasons. Some reported that smoking in $\mathrm{HV}$ had become a more conscious and less automatic act.

Yes, because if you just sit there and you are allowed to smoke everywhere, you just

keep on smoking and now you have to think about it. (\#2, $20 \mathrm{M}, 10 \mathrm{cig} / \mathrm{day})$

In addition, because they did not feel like going outside or to a smoking room to have a smoke, they smoked less in HV.

You are not allowed to smoking inside so you grab a smoke less easily. Because you don't always feel like going outside, you really smoke a lot less. (\#12, $24 \mathrm{M}, 15 \mathrm{cig} / \mathrm{day})$ The cigarette has to remain pleasurable and I don't like it at all, if my legs are shaking from the cold while having a cigarette. Then I feel like... in that case I'd rather not smoke. Then, I will smoke again when I get home or something. (\#18, 24 F, 19 cig/day)

\section{Smoking behaviour (in general)}

Some participants reported to smoke less in general or that they had made a quit attempt since the HV smoking ban. Others reported that they did not reduce their smoking and it appeared that they made a conscious decision to keep smoking.

I thought to myself, I'll be happy continuing smoking. I don't have a reason of some sort for it, but.... at some point you are not allowed to do anything here anymore. (\#2, 20 M, 10 cig/day)

However, no one indicated to have started to smoke more since the HV smoking ban.

\section{Discussion}

The study indicates that increasing smoke-free legislation, such as the smoking ban in $\mathrm{HV}$, did not leave smokers who were interviewed, untouched. It appears that the HV smoking ban, two years after its instatement, is still very vivid to smokers who go out to HV. To some participants, smoking and 'going out' are intricately connected, as are drinking alcohol and smoking. Self-awareness theory (Duval \& Silvia, 2002) and the theory of social exclusion (Abrams et al., 2005) aided in explaining how the Dutch smoking ban affected continuing smokers who participated in the present study. As such, the present study helps to gain a better understanding of how lower SES smokers make sense of a changing policy environment and the experience of 'denormalisation' of smoking in their everyday lives.

According to Ritchie et al. (2010a), a more regulated environment creates more awareness of perceived social sanctions. Indeed, most participants felt increasingly aware of not meeting the norm that was put forward by the smoke-free legislation, making them feel more uncomfortable with (their) smoking. This was reflected in the negative labelling of their smoking and smoker status. Furthermore, in line with 
Ritchie et al. (2010a), the physical separation of smokers and non-smokers appeared to lead some participants to feel socially excluded.

As a result of smoke-free legislation, most of the smokers we interviewed had an increased awareness of the (negative) health and social aspects of smoking and changed their attitudes toward (own) smoking. They felt that they could no longer possess a neutral stance towards smoking and the ban. They either no longer wanted to be a smoker and move more towards quitting smoking or they made a conscious decision to not cut down on their smoking and remain a smoker, despite perceiving increasingly negative connotations attached to being a smoker, which is in accordance with Bell et al. (2010). Some participants evaluated the smoking ban in a positive manner because of its benefits for public health and for non-smokers. Others were more rejecting of the ban, because they felt that there was not enough support and grounds for it. In line with Bell et al. (2010), the ban was perceived by some smokers to have far reaching consequences, limiting their freedom and opportunities for socialisation. Patronage of $\mathrm{HV}$ did not change for some, because other aspects of going out were more important to them than smoking, e.g. the atmosphere. Some participants stayed at home and avoided bars completely, while still others avoided smoke-free bars and actively searched for non-compliant bars. This, although not explicitly mentioned in this study, is likely to stem from a preference for environments where they do not risk disapproval from others (Bell et al., 2010; Ritchie et al., 2010a, 2010b).

It is important to note that in the Netherlands, two years after the HV smoking ban, approximately $50 \%$ of bars and night clubs did not comply with the measure. This is likely to be related to certain features of the policy and of its implementation (Nagelhout, Mons, et al., 2011), such as having a 'self-regulation' period of three months after the introduction of the ban, during which venue owners only got a warning for violations. Furthermore, unlike most other countries that implemented a more successful smoke-free law, smoking rooms were allowed, and only HV owners, and not the smokers themselves could be fined. Quite some bars explicitly demonstrated their non-compliance, for instance, by having a money box in which customers could donate money to be able to pay a fine in case the bar owner would be charged. Moreover, in 2010 the law was adapted, as a result of which smoking in bars smaller than $70 \mathrm{~m}^{2}$ without employees became legalised again.

Based on interviews with 18 Dutch smokers, several patterns of responses could be discerned. Some participants felt less comfortable with being a smoker and move more towards becoming a non-smoker, i.e. 'active quitting', which has similarities with the 'reluctant' smoker as described by Poland et al. (2000). Other participants perceived that they were too much addicted to actually engage in the process of quitting smoking, i.e. 'feeling victimised', which reflected a sense of helplessness about their ability to quit smoking (Bell et al., 2010). This particular pattern has not been previously identified by Poland et al. (2000). Still others complied for the purpose of 'fitting in', i.e. being a socially conscious smoker. However, their (implicit) attitude towards smoking as well as their intentions to quit smoking appeared to have not changed. This response can be regarded as that of the 'considerate' smoker (Poland et al., 2006), or 'easy going' smoker (Poland et al., 2000), i.e. a smoker who complies with the ban for social acceptance, but for whom the ban does not affect their (implicit) attitude towards smoking. According to Ritchie et al. (2010b), this response is motivated by a desire to achieve social acceptance, to minimise social disapproval and to avoid stigmatisation. Finally, we 
found that other participants were more rejecting of the ban; they identified more with smokers and became less likely to change their smoking behaviour ('rejection'), similar to the so-called 'adamant' smoker (Poland et al., 2000).

Responses of smokers to smoke-free legislation are important, since they are likely to influence future psychological and behavioural responses to new smoke-free legislation. Future research should therefore focus on whether the responses that were found in this study can be quantified and examine how these responses are related to certain features of the instatement, design and communication of smoking restrictions. For example, the patterns that we discerned in the present study as response to the HV smoking ban could be validated in a quantitative study, investigating whether they also emerge in larger samples of smokers in the general population as quite distinct sets of interrelated behavioural and psychological responses. It would also be interesting to examine whether these patterns exist in all, and not only lower SES smokers. Therefore, this type of study should preferably be carried out among a large sample that is representative of all smokers. For this particular research question a cross-sectional design would suffice. However, if the patterns can be validated, it would also be of importance to examine whether these patterns are predictive of future behaviour, in which instance a prospective design would be required. In addition, examining what higher and lower SES smokers perceive as what the (dynamic) role of SES is in response to anti-smoking restrictions - something we did not explicitly focus on in the present study - is also likely to yield relevant insights. Finally, more insight into the factors, that may help to have a better understanding of the content of the (psychological) differences between the various responses we identified in the present study, is needed. In line with Cockerham et al. (1997), who state that 'lifestyles are opportunity structures in that people adopt them for the gains they feel they can acquire, which include both a material form to their self-identity and an anchor in particular social constellation of style and activity (p. 337)', we propose that self-identity and social influences are promising candidates in this respect.

An interesting issue feature of the Dutch smoke-free legislation designed to meet smokers in their needs, is the smoking room; a separate room within the HV in which smokers are allowed to smoke. Paradoxically, smoking rooms were rated negatively by the vast majority of participants in our study. Moreover, it led to selfstigmatisation; some participants label themselves and their smoking (more) negatively, e.g. as 'pathetic' or 'weak'. The separation of smokers from non-smokers by means of smoking rooms is likely to have contributed to increased felt stigma (Bayer \& Stuber, 2006; Ritchie et al., 2010a). Stigmatisation may cause depression, less self-esteem and loss of social support (Berger, Ferrans, \& Lashley, 2001) and may discourage smokers from quitting, especially smokers of a lower SES (Farrimond \& Joffe, 2006).

Exclusion is an essential part of stigma (Major \& Eccleston, 2005) and feelings of exclusion were reflected in some participants' reports of feeling like an outcast or pariah, while smoking in designated smoking areas. Arguably, the smoke-free legislation contributes to social exclusion of smokers, because it provides a justification for the moral exclusion of smokers (Major \& Eccleston, 2005). It is important to consider these effects of (future) smoking restrictions on smokers and the societal context in which it is being implemented, because at an individual level, feelings of exclusion could lead to defensive denial as well as self-defeating behaviours (e.g. smoking). Moreover, at a communal level social exclusion leads to 
environments in which inequalities and conflict are likely to increase (Twenge \& Baumeister, 2005). In a sociological and philosophical analysis it was argued that the increasing stigmatisation of smokers that is connected to smoking restriction policies is likely to increase social inequalities (Graham, 2012).

We found that certain biases in the perception in our sample of continuing smokers may have played a role in their predominantly negative evaluation of the smoke-free legislation. For example, one participant (erroneously) mentioned that the prevalence of smokers in the Netherlands was $80 \%$ at the time the smoking ban was introduced and some smokers (again mistakenly) thought that non-smokers were not bothered at all by smoking in bars. The Dutch smoking ban was introduced without implementing an accompanying media campaign to educate the public about public health reasons for the smoke-free legislation and levels of acceptance were low (i.e. $44 \%$ in 2008; European Commission, 2009). It is likely that when the public, both smoker and non-smoker, would be better educated about the grounds on which smoke-free legislation is based, when it is focused more on its health benefits, and when smoke-free legislation is strong and comprehensive, such biases in perception may be prevented and its acceptance increased (Hyland et al., 2009; Nagelhout, Mons, et al., 2011).

Some limitations to the study should be noted here. For example, a response bias may have occurred, i.e. the volunteers, who were willing to participate, were possibly more involved in the topic of smoking and more concerned with the effect of the HV smoking ban. This may imply that respondents were either more willing to quit smoking, or that they were more opposing to the smoking ban, and thus less representative of the general population of smokers in the Netherlands. Particularly, the two participants who were recruited from the Smokers' Rights Group may have been inclined to not only reveal their own opinion and experience, but also to express more political views. However, our main purpose was to find respondents from all different 'smoker-segments', to increase insight into the diversity of possible responses, and we have therefore recruited smokers via a great variety of sources, doing our utmost best to have all sorts perspectives incorporated in this study.

Furthermore, since the study was conducted two to two-and-a-half years after the introduction of the HV smoking ban, a 'recall bias' may have occurred. However, because of the nature of the study, and its particular focus on the present psychological state of the smoker referring to perceived changes and not to actual changes, this is not particularly problematic, but rather an inherent part of the study design. A further possible advantage of this longer period of time between the HV smoking ban and our study, is that participants had had more time to develop a more sophisticated opinion of the smoking ban based on their widespread experience with it.

Finally, we would like to point out that all authors are at present non-smokers, although some of us have smoked in the past. Naturally, this may have influenced our thinking as well as our interpretation of the data. Two of us (MW \& GN) are scientists employed by the Dutch expert centre on Tobacco Control, Stivoro, and Maastricht University, and involved in advising the government and other organisations on smoking reduction and prevention. Another author (AD) is a scientist, who, as a psychologist, has counselled many smokers on how to quit smoking. The two principal investigators of the study ( $\mathrm{SH} \& \mathrm{WG}$ ) are health psychologists and scientists, with a main interest in understanding and changing health behaviours. Thus, all authors are active in the field of prevention, and have a 
focus on how to enhance healthy lifestyles. However, we believe that by focusing on the psychological state of the smoker and investigating all possible responses from a broad theoretical framework, we have been able to uncover in a truthful manner some of the underlying psychological processes that may occur when measures such as a smoking restriction policy are put into effect.

In conclusion, the present study provides more insight into how 18 lower educated continuing smokers experienced the smoke-free legislation in $\mathrm{HV}$ as part of an increasing anti-smoker climate. We used temporal comparisons to assess how they perceived changes since the instatement of the smoke-free legislation and used theories of self-awareness and social exclusion for data interpretation. In short, while it was previously possible for them to possess more of a neutral stance towards smoking, the smoking ban appears to have led them to reevaluate their stance towards smoking. Although the smoke-free legislation was not aimed primarily at making smokers quit, it appeared from our study that some participants cut down or (temporarily) quit smoking as a result of it. More generally, the present study indicates that negative sideeffects on some continuing smokers may also occur, e.g. some choose to continue smoking and regard themselves more strongly as smokers. As argued here, this response may (partly) be a result of smokers feeling socially excluded as a result of smoke-free legislation. It cannot be concluded from this study whether the study results only, or most prominently, apply to lower SES-smokers. Ultimately however, future research, should aim to uncover how the design, communication and implementation of smoke-free legislation can best maximise its benefits and minimise its negative sideeffects, while accounting for differences in social class (cf. Graham, 2012).

\section{Acknowledgements}

We would like to thank all the interviewees who participated in the study and all the people who helped in the design, writing, coding and translating. Furthermore, we are greatly indebted to two anonymous reviewers who provided valuable suggestions for the improvement of a previous version of the manuscript. This study was performed under MIRO, a national program for optimising smoking cessation. MIRO is an initiative of Pfizer and Caphri. This project is supported by an unrestricted grant from Pfizer and Caphri. The views expressed are those of the authors and not necessarily of the funders.

\section{References}

Abrams, D., Hogg, M.A., \& Marques, J.M. (2005). The social psychology of inclusion and exclusion. New York, NY: Psychology Press.

Alamar, B., \& Glantz, S.A. (2006). Effect of increased social unacceptability of cigarette smoking on reduction in cigarette consumption. American Journal of Public Health, 96, $1359-1363$.

Albert, S. (1977). Temporal comparison theory. Psychological Review, 84, 485-503.

Bayer, R., \& Stuber, J. (2006). Tobacco control, stigma, and public health: Rethinking the relations. American Journal of Public Health, 96, 47-50.

Bell, K., McCullough, L., Salmon, A., \& Bell, J. (2010). 'Every space is claimed': Smokers' experiences of tobacco denormalisation. Sociology of Health \& Illness, 32, 914-929.

Berger, B.E., Ferrans, C.E., \& Lashley, F.R. (2001). Measuring stigma in people with HIV: Psychometric assessment of the HIV stigma scale. Research in Nursing \& Health, 24, 518-529.

Borland, R., \& Owen, N. (1995). Need to smoke in the context of workplace smoking bans. Preventive Medicine, 24, 56-60. 
Braun, V., \& Clarke, V. (2006). Using thematic analysis in psychology. Qualitative Research in Psychology, 3, 77-101.

Brown, A., Moodie, C., \& Hastings, G. (2009). A longitudinal study of policy effect (smokefree legislation) on smoking norms: ITC Scotland/United Kingdom. Nicotine \& Tobacco Research, 11, 924-932.

Carver, C.S., \& Scheier, M.F. (1978). Self-focusing effects of dispositional self-consciousness, mirror presence, and audience presence. Journal of Personality and Social Psychology, 36, 324-332.

Chapman, S., \& Freeman, B. (2008). Markers of the denormalisation of smoking and the tobacco industry. Tobacco Control, 17, 25-31.

Cockerham, W.C., Rutten, A., \& Abel, T. (1997). Conceptualizing contemporary health lifestyles: Moving beyond Weber. Sociological Quarterly, 38, 321-342.

Dijkstra, A., Borland, R., \& Buunk, B.P. (2007). The motivation to stay abstinent in ex-smokers: Comparing the present with the past. Addictive Behaviors, 32, 2372-2376.

Duval, T.S., \& Silvia, P.J. (2002). Self-awareness, probability of improvement, and the selfserving bias. Journal of Personality and Social Psychology, 82, 49-61.

Duval, T.S., \& Wicklund, R.A. (1972). A theory of objective self-awareness. New York, NY: Academic Press.

European Commission (2009). Survey on tobacco: Analytical report. Hungary: The Gallup Organisation. Eurobarometer, \#253.

Farrimond, H.R., \& Joffe, H. (2006). Pollution, peril and poverty: A British study of the stigmatization of smokers. Journal of Community \& Applied Social Psychology, 16, 481-491.

Graham, H. (2012). Smoking, Stigma and Social Class. Journal of Social Policy, 41, 83-99.

Hargreaves, K., Amos, A., Highet, G., Martin, C., Platt, S., Ritchie, D., \& White, M. (2010). The social context of change in tobacco consumption following the introduction of 'smokefree' England legislation: A qualitative, longitudinal study. Social Science \& Medicine, 71, 459-466.

Huisman, M., Van Lenthe, F.J., Giskes, K., Kamphuis, C.B.M., Brug, J., \& Mackenbach, J.P. (2012). Explaining socio-economic inequalities in daily smoking: A social-ecological approach. European Journal of Public Health, 22, 238-243.

Hyland, A., Higbee, C., Borland, R., Travers, M., Hastings, G., Fong, G.T., \& Cummings, K.M. (2009). Attitudes and beliefs about secondhand smoke and smoke-free policies in four countries: Findings from the International Tobacco Control Four Country Survey. Nicotine \& Tobacco Research, 11, 642-649.

Kuckartz, U. (2007). MAXQDA 2007 reference manual for Windows 2000 and XP (J. Poppe, Trans.). Marburg, Germany: Verbi Software.

Louka, P., Maguire, M., Evans, P., \& Worrell, M. (2006). 'I think that it's a pain in the ass that I have to stand outside in the cold and have a cigarette' - Representations of smoking and experiences of disapproval in UK and Greek smokers. Journal of Health Psychology, 11, 441-451.

Major, B., \& Eccleston, C.P. (2005). Stigma and social exclusion. In D. Abrams, M.A. Hogg, \& J.M. Marques (Eds.), The social psychology of inclusion and exclusion (pp. 63-87). New York, NY: Psychology Press.

McLaughlin-Volpe, T., Aron, A., Wright, S.C., \& Lewandowski Jr, G.W. (2005). Exclusion of the self by close others and by groups: Implications of the self-expansion model. In D. Abrams, M.A. Hogg, \& J.M. Marques (Eds.), The social psychology of inclusion and exclusion (pp. 113-134). New York, NY: Psychology Press.

Menninga, K., Dijkstra, A., Gebhardt, W.A., \& Siero, F. (2011). "I'm better off now": The role of temporal comparisons and exposure evaluations in smoking cessation. Journal of Health Psychology, 16, 1082-1090.

Mons, U., Nagehout, G.E., Guignard, R., McNeill, A., Van den Putte, B., Willemsen, M.C., ... Breitling, L.P. (2012). Comprehensive smoke-free policies 
attract more support from smokers in Europe than partial policies. European Journal of Public Health, 22, 10-16.

Nagelhout, G.E., De Korte, J.D, De Boer, D., Kunst, A.E., Van der Meer, R.M., De Vries, H., ... Willemsen, M.C. (2012). Trends in socioeconomic inequalities in smoking prevalence, consumption, initiation, and cessation between 2001 and 2008 in the Netherlands: Findings from a national population survey. BMC Public Health, 12, 303-312.

Nagelhout, G.E., De Korte, J.D., Van der Meer, R.M., Zeegers, T., Van Gelder, B.M., \& Willemsen, M.C. (2011). Themapublicatie: Sociaaleconomische verschillen in roken in Nederland 1988-2010. Den Haag: STIVORO - voor een rookvrije toekomst.

Nagelhout, G.E., Mons, U., Allwright, S., Guignard, R., Beck, F., Fong, G.T., et al. (2011). Prevalence and predictors of smoking in 'smoke-free' bars. Findings from the International Tobacco Control (ITC) Europe Surveys. Social Science \& Medicine, 72, $1643-1651$.

Nagelhout, G.E., Willemsen, M.C., \& de Vries, H. (2011). The population impact of smokefree workplace and hospitality industry legislation on smoking behaviour. Findings from a national population survey. Addiction, 106, 816-823.

Poland, B.D., Chen, J.E., Ashley, M.J., Adlaf, E., Ferrence, R., Pederson, L.L., .. Rahpael, D. (2000). Heterogeneity among smokers and non-smokers in attitudes and behaviour regarding smoking and smoking restrictions. Tobacco Control, 9, 364-371.

Poland, B., Frohlich, K., Haines, R.J., Mykhalovskiy, E., Rock, M., \& Sparks, R. (2006). The social context of smoking: The next frontier in tobacco control? Tobacco Control, 15, $59-63$.

Reid, J.L., Hammond, D., Boudreau, C., Fong, G.T., \& Siahpush, M. (2010). Socioeconomic disparities in quit intentions, quit attempts and smoking abstinence among smokers in four western countries: Findings from the international tobacco control four country survey. Nicotine \& Tobacco Research, 12(S1), S20-S33.

Ritchie, D., Amos, A., \& Martin, C. (2010a). 'But it just has that sort of feel about it, a leper'stigma, smoke-free legislation and public health. Nicotine \& Tobacco Research, 12, $622-629$.

Ritchie, D., Amos, A., \& Martin, C. (2010b). Public places after smoke-free - A qualitative exploration of the changes in smoking behaviour. Health \& Place, 16, 461-469.

Schaap, M.M., \& Kunst, A.E. (2009). Monitoring of socio-economic inequalities in smoking: Learning from the experiences of recent scientific studies. Public Health, 123, 103-109.

Siahpush, M., McNeill, A., Borland, R., \& Fong, G. T. (2006). Socioeconomic variations in nicotine dependence, self-efficacy, and intention to quit across four countries: Findings from the International Tobacco Control (ITC) Four Country Survey. Tobacco Control, $15,71-75$.

Silvia, P.J., \& Duval, T.S. (2001). Objective self-awareness theory: Recent progress and enduring problems. Personality and Social Psychology Review, 5, 230-241.

Sorensen, G., Emmons, K., Stoddard, A.M., Linnan, L., \& Avrunin, J. (2002). Do social influences contribute to occupational differences in quitting smoking and attitudes towards quitting? American Journal of Health Promotion, 16, 135-141.

Twenge, J.M., \& Baumeister, R.F. (2005). Social exclusion increases aggression and selfdefeating behavior while reducing intelligent thought and prosocial behavior. In D. Abrams, M.A. Hogg, \& J.M. Marques (Eds.), The social psychology of inclusion and exclusion (pp. 27-46). New York, NY: Psychology Press.

Warner, K.E., \& Burns, D.M. (2003). Hardening and the hard-core smoker: Concepts, evidence, and implications. Nicotine \& Tobacco Research, 5, 37-48. 